Check for updates

Cite this: Chem. Sci., 2018, 9, 4866

\title{
Predicting the DNP-SENS efficiency in reactive heterogeneous catalysts from hydrophilicity $\dagger$
}

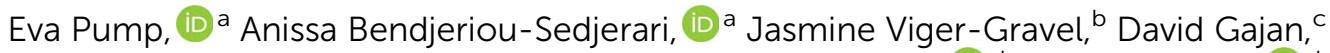 \\ Baptiste Scotto, ${ }^{a}$ Manoja K. Samantaray, ${ }^{a}$ Edy Abou-Hamad, (D) d Andrei Gurinov, (DD d \\ Walid Almaksoud, ${ }^{a}$ Zhen Cao, ${ }^{a}$ Anne Lesage, ${ }^{c}$ Luigi Cavallo, (D) a Lyndon Emsley (DD *b \\ and Jean-Marie Basset (iD) *a
}

Identification of surfaces at the molecular level has benefited from progress in dynamic nuclear polarization surface enhanced NMR spectroscopy (DNP SENS). However, the technique is limited when using highly sensitive heterogeneous catalysts due to secondary reaction of surface organometallic fragments (SOMFs) with stable radical polarization agents. Here, we observe that in non-porous silica nanoparticles (NPs) $\left(d_{\text {particle }}=15 \mathrm{~nm}\right.$ ) some DNP enhanced NMR or SENS characterizations are possible, depending on the metal-loading of the SOMF and the type of SOMF substituents (methyl, isobutyl, neopentyl). This unexpected observation suggests that aggregation of the nanoparticles occurs in non-polar solvents (such as ortho-dichlorobenzene) leading to (partial) protection of the SOMF inside the interparticle space, thereby preventing reaction with bulky polarization agents. We discover that the DNP SENS efficiency is correlated with the hydrophilicity of the SOMF/support, which depends on the carbon and SOMF concentration. Nitrogen sorption measurements to determine the BET constant $\left(C_{\mathrm{BET}}\right)$ were performed. This constant allows us to predict the aggregation of silica nanoparticles and consequently the efficiency of DNP SENS. Under optimal conditions, $C_{\mathrm{BET}}>60$, we found signal enhancement factors of up to 30

Received 1st February 2018

Accepted 16th April 2018

DOI: 10.1039/c8sc00532j

rsc.li/chemical-science organometallic chemistry (SOMC) are silica nanoparticles (NPs). ${ }^{1,9,10}$ Surface silanols generated by a high temperature dehydroxylation process under vacuum $\left(700^{\circ} \mathrm{C}, 10^{-5} \mathrm{mbar}\right)$ act as anchor sites for early transition metals leading to the design of well-defined heterogeneous catalysts. ${ }^{11}$ This strategy, also known as "Catalysis by Design", requires methods for unambiguous characterization of these species at the atomic level, usually through advanced spectroscopic techniques such as EXAFS and multi-dimensional solid-state NMR (SS NMR) spectroscopy. ${ }^{\mathbf{1} 10,12,13}$ The low intrinsic sensitivity of NMR is a major drawback for atomic level characterization of SOMFs due to prohibitively low signal-to-noise ratios and long experimental times. This problem can be overcome by an emerging technique called dynamic nuclear polarization surface enhanced NMR spectroscopy (DNP SENS). ${ }^{14-16}$ DNP SENS can increase the signal intensity of conventional NMR spectra by two orders of magnitude, and has been applied to a range of surface systems. ${ }^{17-28}$ Recently, it has led to the first complete threedimensional structure of a SOMF on a silica surface. ${ }^{29}$ The method requires the addition of stable radicals as sources of polarization, usually nitroxide biradicals such as TEKPol, ${ }^{14,16}$ which is usually added through incipient wetness impregnation $(\mathrm{IWI})^{30}$ and acts as a source of unpaired electrons. In situ microwave ( $\mu$ wave) irradiation transfers electron polarization to the surrounding nuclei (usually protons), and is followed by 
spin diffusion and cross-polarization (CP) to the nuclei of interest. ${ }^{16,31}$ The presence of a biradical species means that DNP SENS has only rarely been applicable in SOMC, due to the reactivity of nitroxide radicals with the SOMF. ${ }^{32,33}$ Therefore this precludes the characterization of the most interesting catalytic species. There is thus a need for a non-destructive strategy for DNP SENS characterization of SOMFs. A range of different formulations for DNP SENS have recently been proposed. ${ }^{19,27,28,34-39,67}$ In particular it has been shown that reactive surface species can be studied either by protecting them inside mesoporous supports and using bulky radicals that are too large to enter the pores, ${ }^{27,39}$ or by using polarizing agents incorporated into dendrimers in order to avoid contact between the radical and the surface species. ${ }^{28}$ These approaches led to DNP signal enhancements for the surface species $\left(\varepsilon_{\mathrm{C}}, \mathrm{CP}\right.$ (SOMF)) of between 10 and 30. However, neither strategy is trivial to implement. Moreover, Perras et ll $^{\mathbf{4 0}}$ recently demonstrated that the radicals may physisorb on surfaces, and thus that the radical concentration should be optimized as a function of specific surface area in alumina, silica and mesoporous carbon samples. In the case of reactive surface species, the affinity between the radical and the surface will lead to the decomposition of active sites grafted on the support.

Here, we introduce a strategy based on controlled aggregation for reactive samples which can be applied to silica nanoparticles. Aggregation leads to exclusion of bulky biradicals, thereby avoiding direct contact between the SOMF and the polarization agent. We show that the DNP SENS efficiency can be predicted by measuring the hydrophilicity of the surfaces. We find signal enhancement factors of up to 30, corresponding to a reduction in experimental acquisition time by a factor of 900 with respect to conventional SSNMR. In this way we investigate a library of highly sensitive supported organometallic complexes bearing alkyl-ligands of various coordinations and sizes: $\mathrm{Ti}\left(\mathrm{CH}_{2}{ }^{t} \mathrm{Bu}\right)_{4}$ I, $\mathrm{Zr}\left(\mathrm{CH}_{2}{ }^{t} \mathrm{Bu}\right)_{4}$ II, $\mathrm{WMe}_{6}$ III, W( $\left.\equiv \mathrm{C}^{t} \mathrm{Bu}\right)\left(\mathrm{CH}_{2^{-}}\right.$ $\left.{ }^{t} \mathrm{Bu}\right)_{3} \mathbf{I V}, \mathrm{ZnMe}_{2} \mathbf{V}$ and $\mathrm{Ga}\left({ }^{i} \mathrm{Bu}\right)_{3}$ VI.

Attraction between silica NPs is mainly governed by hydrogen bonding ${ }^{\mathbf{4 1 4 2}}$ and van der Waals interactions ${ }^{\mathbf{4 3}}$ and leads to aggregation. Hydrophilic silica NPs (e.g. Aerosil-200 dehydroxylated at $700{ }^{\circ} \mathrm{C}$ ) aggregate to a much higher extent in solvents with low polarity compared to NPs that have hydrophobic surfaces. ${ }^{44-48}$ Surface modification of silica by SOMFs has three main effects: (i) when there is lower concentration of remaining $[\equiv \mathrm{SiOH}]$ on the NP surface, agglomeration due to the formation of inter-particle hydrogen bonds between two nanoparticles is weakened, (ii) the presence of bulky SOMFs on the surface reduces aggregation of NPs due to steric hindrance ${ }^{\mathbf{4 8}}$ and (iii) the presence of hydrophobic alkyl groups in the SOMFs in non-polar solvent also reduces the propensity for aggregation. ${ }^{49}$ We expect all of this to have an effect on DNP efficiency. For example, the presence of surface methyl groups has been shown in the past to strongly affect DNP enhancements. ${ }^{\mathbf{5 0}}$

With these observations in mind, here we suggest three parameters that influence the aggregation of NPs and can determine the applicability of DNP SENS for characterization of reactive species: ligand/solvent polarity, ligand size, and SOMF surface loading. A controlled aggregation of silica NPs allows for the protection of the SOMF from TEKPol while maintaining a reasonable transfer of polarization through the solvent inside the interparticle space of the aggregates. Ideal conditions are found based on the loading of the SOMF, which can be measured by elemental analysis, and the hydrophobicity of the material, which is obtained from nitrogen sorption measurements $\left(C_{\mathrm{BET}}\right.$, vide infra $) .{ }^{51-53}$

\section{Results and discussion}

Reactions of organometallic complexes I-VI were performed with various SOMF loadings (of 0.2 (low), 0.5 (med) and 1.0 eq. $[\mathrm{SOMF}] / \mathrm{g}[\equiv \mathrm{SiOH}]($ high $))$. The reactions were either conducted at room temperature (I, II, IV, V and VI) or $-40{ }^{\circ} \mathrm{C}$ (III) with partially dehydroxylated silica at $700{ }^{\circ} \mathrm{C} \mathrm{SiO} \mathrm{S}_{2}$, $700(0.30 \pm$ $0.05 \mathrm{mmol}$ of $[\equiv \mathrm{SiOH}] / \mathrm{g}$ of $\mathrm{SiO}_{2}$, 700) in $n$-pentane leading to SOMFs 1-6 (Table 1) according to literature protocols. ${ }^{54-59}$ More detailed information regarding grafting conditions and characterization can be found in the ESI. $\dagger$ FT-IR spectra (Fig. S1, ESI $\dagger$ ) generally illustrate the decrease of the $[\equiv \mathrm{SiOH}]$ vibrational band intensity at $3740 \mathrm{~cm}^{-1}$ and the increase of the intensity of $\nu(\mathrm{C}-\mathrm{H})\left(3100-2700 \mathrm{~cm}^{-1}\right)$ and $\delta(\mathrm{CH})$ bands $\left(1569 \mathrm{~cm}^{-1}\right.$ and $1361 \mathrm{~cm}^{-1}$ ) with increasing SOMF concentration. The SOMF concentration and the carbon content were determined by elemental analysis $(\mathrm{ESI} \dagger)$, and the results are summarized in Table 1.

Additionally, nitrogen sorption measurements were performed to determine the value of $C_{\mathrm{BET}}$, which is used to assess the surface polarity of the silica. ${ }^{51-53}$ More precisely, $C_{\mathrm{BET}}$ expresses the strength of the adsorbate-adsorbent interaction and is related to the excess enthalpy of condensation of nitrogen molecules adsorbed on the first monolayer. The $C_{\mathrm{BET}}$ value is determined from the BET analysis of the portion of the isotherm between relative pressures $\left(p / p_{0}\right)$ of 0.05 and 0.20 according to the following eqn (1):

$$
C_{\mathrm{BET}}=\frac{V_{\mathrm{ads}}}{p / p_{0}}+V_{\mathrm{ads}}
$$

where $V_{\text {ads }}$ is the quantity of gas adsorbed per unit adsorbent mass and $p / p_{0}$ is the relative pressure at adsorption equilibrium. $C_{\mathrm{BET}}$ is a measure of hydrophilicity, with a high value expected for hydrophilic surfaces, and a low value for hydrophobic surfaces. ${ }^{51-53} C_{\mathrm{BET}}$ for hydrophilic silica dehydroxylated at $700{ }^{\circ} \mathrm{C} \mathrm{O}$ is 81 , and serves as a reference in this study (Table 1 , entry 1). The value decreases to around 28 if silica is fully passivated with trimethylsilyl (TMS) and therefore becomes hydrophobic (Fig. S2, ESI $\dagger$ ). ${ }^{51,52}$ To determine the correlation between the surface polarity and the aggregation properties of silica NPs, we performed transmission electron microscopy (TEM) of non-passivated (0) and fully TMS-passivated (0-high) silica NPs in non-polar media (Fig. S3, ESI $\dagger$ ). The results show that indeed more hydrophobic silica NPs are better dispersed in a hydrophobic medium. ${ }^{60}$ Investigating the aggregation of silica NPs covered with SOMFs 1-6 by TEM was not feasible, as these systems are highly air/moisture sensitive, which might change the attraction properties under given conditions. 
Table 1 Summary of metal ( $\left.C_{\text {SOMF }}\right)$ and carbon ( $\left.c_{\text {carbon }}\right)$ concentrations and $C_{\text {BET }}$ determined for silica70o $(0)$ and SOMFs $1-6$ at various SOMF concentrations (low, med, and high)

\begin{tabular}{|c|c|c|c|c|c|}
\hline Entry & Sample & Structure & $c_{\text {SOMF }}\left(\mathrm{mmol} \mathrm{g}_{\text {silica }}{ }^{-1}\right)$ & $c_{\text {carbon }}\left(\mathrm{mmol} \mathrm{g}_{\text {silica }}{ }^{-1}\right)$ & $C_{\mathrm{BE}}$ \\
\hline 1 & $\mathbf{0}$ & & 0 & 0 & 81 \\
\hline 2 & 1-med & & 0.179 & 2.70 & 43 \\
\hline 3 & 1-low & & 0.099 & 1.59 & 57 \\
\hline 4 & 2-med & & 0.153 & 1.93 & 54 \\
\hline 5 & 2-low & & 0.044 & 0.76 & 58 \\
\hline 6 & 3-med & & 0.125 & 0.65 & 65 \\
\hline 7 & 3-low & & 0.070 & 0.34 & 75 \\
\hline 8 & 4-high & & 0.234 & 3.59 & 32 \\
\hline 9 & 4-med & & 0.114 & 1.80 & 50 \\
\hline 10 & 4-low & & 0.065 & 0.89 & 65 \\
\hline 11 & 5-med & & 0.103 & $0.19^{a}$ & 71 \\
\hline 12 & 5-low & & 0.049 & $0.02^{b}$ & 78 \\
\hline 13 & 6-high & & 0.200 & $2.41^{a}$ & 42 \\
\hline 14 & 6-med & & 0.110 & $1.39^{a}$ & 54 \\
\hline
\end{tabular}

${ }^{a}$ Late transition metals are prone to open siloxane bridges leading to a higher than expected carbon/metal ratio. ${ }^{b}$ The detection limit of the instrument is $0.2 \mathrm{wt} \%$ carbon.

The aggregation hypothesis is also supported by free energy calculations (details are provided in the ESI $\dagger$ ), ${ }^{61-63}$ which reflect the effective interaction between particles in solution. Calculations were performed on molecular $\mathrm{T}^{8}$-silsesquioxane models (Fig. S4, ESI $\dagger$ ). Non-functionalized $\left[\mathrm{SiO}_{1.5}(\mathrm{OH})\right]_{8}(\mathbf{M}-\mathbf{0}$, black in Fig. 1) shows a strong tendency towards aggregation between these particles due to the hydrogen-bonding interactions between their $\mathrm{OH}$ groups. After functionalization of four $[\equiv \mathrm{SiOH}]$ with $-{ }^{t} \mathrm{Bu}\left(\mathrm{CMe}_{3}\right)\left(\mathbf{M}-\mathbf{M e}\right.$, blue in Fig. 1) or $-\mathrm{C}\left(\mathrm{CH}_{2}{ }^{t} \mathrm{Bu}\right)_{3}$, $\left(\mathbf{M}-\mathbf{C H}_{2}{ }^{t} \mathbf{B u}\right.$, red in Fig. 1) the attraction between two silsesquioxane molecules decreases with increasing bulkiness of the ligand.

The materials remain more hydrophilic (higher $C_{\mathrm{BET}}$ ) with lower carbon content which holds true for (i) changing the ligand from $-\mathrm{CH}_{2}{ }^{t} \mathrm{Bu}$ to $-{ }^{i} \mathrm{Bu}$ to $-\mathrm{Me}$, (ii) changing the number of ligands and (iii) decreasing the SOMF loading from high $\left(c_{\mathrm{SOMF}}\right.$ $\left.>0.18 \mathrm{mmol} \mathrm{g}_{\text {silica }}{ }^{-1}\right)$ to med $\left(0.1<c_{\mathrm{SOMF}}<0.18 \mathrm{mmol} \mathrm{g}_{\text {silica }}{ }^{-1}\right)$ to low $\left(c_{\mathrm{SOMF}}<0.1 \mathrm{mmol} \mathrm{g}_{\text {silica }}{ }^{-1}\right)$. The $C_{\mathrm{BET}}$ value is around 75 for lower loadings of SOMFs having lower carbon contents (e.g. 5-low, 5-med, and 3-low) and decreases to around 30 for higher loadings of SOMFs with higher carbon content (e.g. 1-med, 4high, and 6-high). The results are illustrated in Fig. 2a.

We have taken seven silica NPs loaded with various SOMFs at different concentrations along the trend line in Fig. $2 \mathrm{~b}$ and investigated them in more detail by DNP SENS: 1-med $\left(C_{\mathrm{BET}}=\right.$ $43)$, 2-med $\left(C_{\mathrm{BET}}=54\right)$, 3-low $\left(C_{\mathrm{BET}}=75\right)$, 3-med $\left(C_{\mathrm{BET}}=65\right)$, 4low $\left(C_{\mathrm{BET}}=65\right)$, 4-med $\left(C_{\mathrm{BET}}=50\right)$ and 4-high $\left(C_{\mathrm{BET}}=32\right)$. DNP SENS experiments of $\mathbf{3}$ and $\mathbf{4}$ are particularly interesting, as the results can be compared to previous experiments where the SOMF was protected inside mesopores of MCM- $41 .^{27}$

For DNP-SENS experiments, ortho-dichlorobenzene $(o \text {-DCB })^{64}$ was used as the solvent because its carbon resonances $(\delta=115-140 \mathrm{ppm})$ do not overlap with the expected ${ }^{13} \mathrm{C}$ chemical shifts of SOMFs for most investigations ${ }^{27}$ (though it 


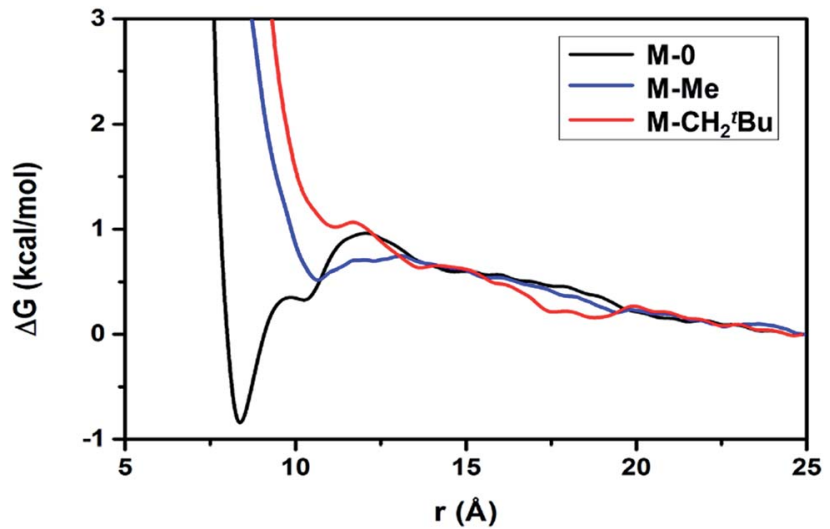

Fig. 1 Free energy as a function of distance $(r)$ between centers of masses of two prototypical silica particles $\mathrm{M}-\mathrm{O}, \mathrm{M}-\mathrm{Me}$ or $\mathrm{M}-\mathrm{CH}_{2}{ }^{\mathrm{t}} \mathrm{Bu}$ illustrates the trend of aggregation between these two particles in $0^{-}$ DCB solution. $\mathrm{M}-\mathrm{O}, \mathrm{M}-\mathrm{Me}$, and $\mathrm{M}-\mathrm{CH}_{2}{ }^{\mathrm{t}} \mathrm{Bu}$ correspond to $\left[\mathrm{SiO}_{1.5}(\mathrm{OH})\right]_{8}$, $\left[\mathrm{SiO}_{1.5}\left(\mathrm{O}^{\mathrm{t}} \mathrm{Bu}\right)_{0.5}(\mathrm{OH})_{0.5}\right]_{8}$, and $\left[\mathrm{SiO}_{1.5}\left(\mathrm{OC}\left(\mathrm{CH}_{2}{ }^{t} \mathrm{Bu}\right)_{3}\right)_{0.5}(\mathrm{OH})_{0.5}\right]_{8}$, respectively. Details of the free energy calculation are summarized in the ESI. $\dagger$

has recently been shown that the solvent resonances can be suppressed if needed). ${ }^{65}$ The maximum solvent ${ }^{1} \mathrm{H}$ enhancement, $\varepsilon_{\mathrm{H}}$, for pure $\mathrm{SiO}_{2,700} 0$ impregnated with a $16 \mathrm{mM}$ solution of TEKPol in $o$-DCB obtained here was $\varepsilon_{\mathrm{H}}=101$ (the TEKPol is inert on silica) and serves in the following as an indicator for estimating the destruction of TEKPol by reaction with the SOMF. Typically, TEKPol (biradical) is added in default (0.6 $\mu \mathrm{mol})$ with respect to the SOMF (1.6-4.7 $\mu \mathrm{mol})$. Depending on the SOMF loading, a SOMF/radical ratio of at least $\geq 1$ is used for DNP SENS experiments. This ratio suggests that the radical should be completely destroyed in all cases if we assume full accessibility of the SOMFs (Table S1, ESI $\dagger$ ). Consequently, no enhancement should be detected. For example, when SOMFs 3 and 4 were immobilized on SBA15 $\left(d_{\text {pore }}=6.0 \mathrm{~nm}\right),{ }^{27}$ we were not able to detect signal enhancements by DNP SENS after the samples were impregnated with TEKPol. We found by quantitative EPR that the radical concentration for 4-high was $94 \%$ lower as compared to non-functionalized silica nanoparticles o ( $1 \mathrm{~h}$ after impregnation), and decreased further with time (99\% lower after $4.5 \mathrm{~h}$ ) (Table S5 and Fig. S9, ESI $\dagger$ ).

Comparing the measured $C_{\mathrm{BET}}$ value with the experimental solvent ${ }^{1} \mathrm{H}$ enhancement factors obtained from DNP SENS experiments in $o$-DCB (Fig. 2b), we observe a correlation between increasing $\varepsilon_{\mathrm{H}}$ and increasing hydrophilicity of silica nanoparticles.

Low levels of functionalization of the silica NPs (such as 1low, 2-low, and 3-med having a $C_{\mathrm{BET}}>60$ ) lead to aggregation of the silica NPs, which partially prevents reaction between TEKPol and the SOMF and hence enables reasonable solvent enhancements $\left(\varepsilon_{\mathrm{H}}>60\right)$. A value in the range of $50<C_{\mathrm{BET}}<60$ is observed for silica NPs loaded with SOMFs bearing $-\mathrm{CH}_{2}{ }^{t} \mathrm{Bu}$ ligands at a medium concentration (2-med and 4-med). The concomitant ${ }^{1} \mathrm{H}$ enhancements are $10<\varepsilon_{\mathrm{H}}<20$. A higher degree of functionalization (1-med and 4-high; $C_{\mathrm{BET}}<50$ ) leads to a higher dispersion of silica NPs and hence SOMFs are more exposed to react with TEKPol, leading to low ${ }^{1} \mathrm{H}$ enhancements $\left(\varepsilon_{\mathrm{H}}<5\right)$.
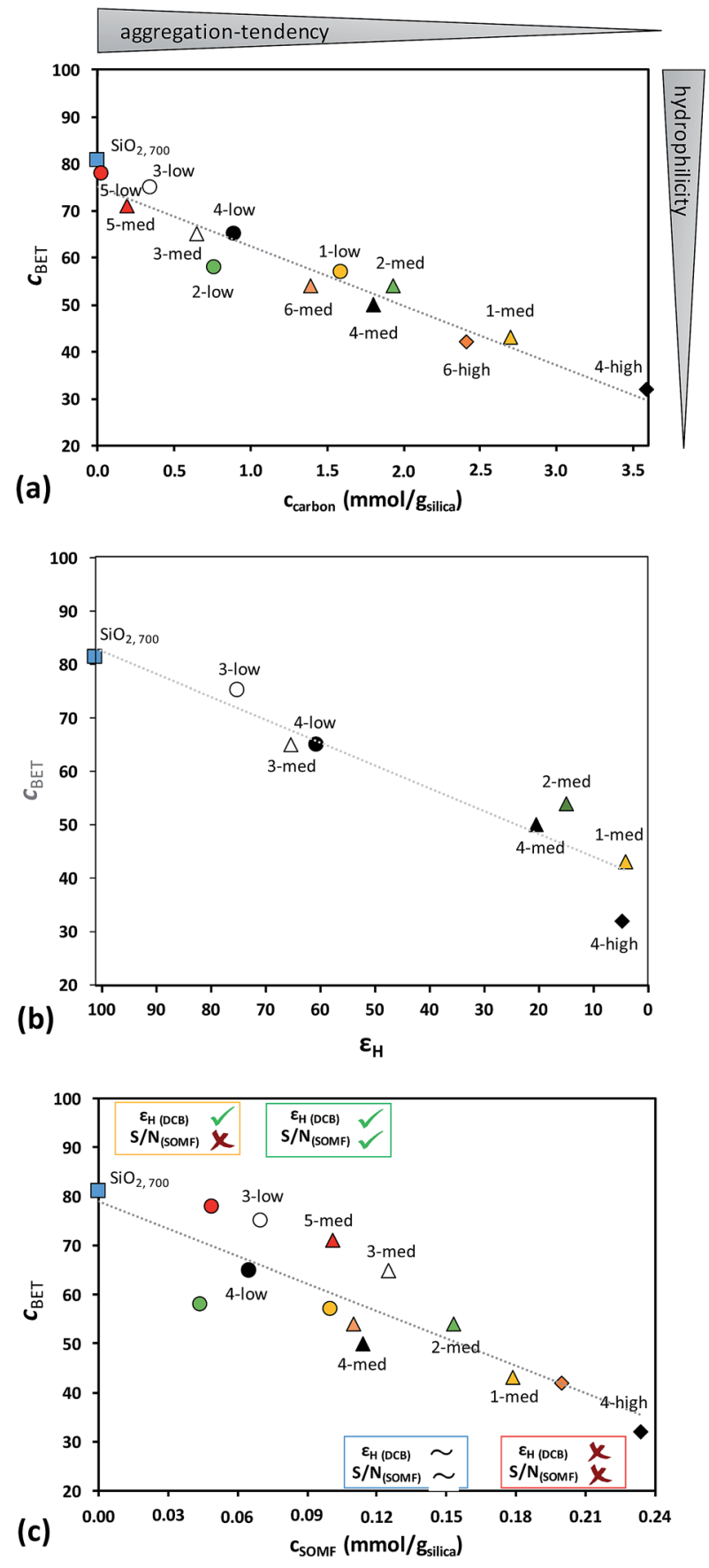

Fig. 2 (a) Correlation of $C_{B E T}$ and $C_{\text {carbon }}$ of SOMFs $1-6$ at various concentrations; (b) correlation of $C_{\mathrm{BET}}$ with ${ }^{1} \mathrm{H}$ enhancement factors $\varepsilon_{\mathrm{H}}$ (o-DCB) and (c) correlation of $C_{\mathrm{BET}}$ and $C_{\mathrm{SOMF}}$ of SOMFs 1-6 at different concentrations. The various regions (yellow, blue, red and green) indicate where DNP SENS measurements are possible and where they are not. $S / N_{(S O M F)}$ corresponds to the signal to noise ratio of the SOMF.

Thus, we see that for successful characterization of the SOMFs by DNP SENS the aggregation tendency of the silica NPs (deduced from the $C_{\mathrm{BET}}$ value) and the concentration of SOMFs are significant, as illustrated in Fig. 2c. Note that in this study all data were recorded at a constant radical concentration. The surface area of the silica samples here is around $200 \mathrm{~m}^{2} \mathrm{~g}^{-1}$, and 
the $16 \mathrm{mM}$ radical concentration used is the optimal TEKPol concentration determined by Perras et al. for silica with $186 \mathrm{~m}^{2} \mathrm{~g}^{-1}$ surface area, ${ }^{40}$ as was determined previously. ${ }^{64}$

Analysis of the data in Fig. 2c leads to the following conclusions:

(I) For $C_{\mathrm{BET}}<60$ and $c_{\mathrm{SOMF}}>0.17 \mathrm{mmol} \mathrm{g}^{-1}$ (1-med and 4high), the (almost) fully passivated SOMF-covered silica NPs are more hydrophobic compared to $\mathrm{SiO}_{2}, 700$ leading to better dispersed particles in non-polar solvents. The SOMF is not protected by the interparticle space and the radical/surface interaction leads to (almost) complete decomposition of the polarizing agent. Hence, (almost) no enhancement $\varepsilon_{\mathbf{H}}$ and surface signal are obtained (Fig. 2 and S7, ESI $\dagger$ ).

(II) For $C_{\mathrm{BET}}<60$ and $0.095<c_{\mathrm{SOMF}}<0.17 \mathrm{mmol} \mathrm{g}^{-1}(2-\mathrm{med}$ and 4-med), the polarization agent is partially destroyed, as observed by the low solvent $\varepsilon_{\mathrm{H}}$ enhancements (10-20), corresponding to a long build-up time $\left(T_{\mathrm{B}, \mathrm{ON}}=18.7 \mathrm{~s}\right)$. The ${ }^{13} \mathrm{C} \mathrm{CP}$ MAS NMR spectra of 2-med $(\mathrm{S} / \mathrm{N}=20)$ as well as 4 -med $(\mathrm{S} / \mathrm{N}=$ 28) showed a low signal-to-noise ratio for $\mathrm{C}\left(\underline{\mathrm{C}} \mathrm{H}_{3}\right)_{3}$ after 10000 and 16000 scans, respectively (Fig. S7, ESI $\dagger$ ). The long build-up time indicates that the biradical is significantly decomposed (a lower radical content in solution will increase $\left.T_{\mathrm{B}}\right) ;{ }^{66}$ however the observed solvent enhancement shows that the residual biradical does succeed in providing a modest enhancement in the surface species.

(III) For $C_{\mathrm{BET}}>60$ and $0.075<c_{\mathrm{SOMF}}<0.13 \mathrm{mmol} \mathrm{g}^{-1}$ (3-med), we obtain the most beneficial properties to enable characterization of the SOMF by DNP SENS. For SOMF 3-med, ${ }^{1} \mathrm{H}$ MAS, ${ }^{13} \mathrm{C}\left(\mathrm{S} / \mathrm{N}=13\right.$ for Me1 after 288 scans), and ${ }^{29}$ Si CP MAS DNP SENS spectra ( $\mathrm{S} / \mathrm{N}=27$ after 1024 scans) with reasonable $\mathrm{S} / \mathrm{N}$ ratios are acquired within 1.5 hours (Fig. 3) with $\varepsilon_{\mathrm{H}}(o$-DCB) $=$ $65.4(0.6), \varepsilon_{\mathrm{C}, \mathrm{CP}}(3$-med $)=27(9)$ and $\varepsilon_{\mathrm{Si}, \mathrm{CP}}(3$-med $)=36(3)$ and with 8, 288 and 1024 scans, respectively. ${ }^{1}{ }^{1} \mathrm{H}^{13}{ }^{13} \mathrm{HETCOR}$ DNP SENS spectrum was recorded in 10 hours (128 scans, 96 increments, $t_{1}=3 \mathrm{~s}$; Fig. S6, ESI $\dagger$ ), which would take 375 days without using DNP SENS.

The success of the experiments is attributed to the aggregation of the SOMF-covered silica NPs in non-polar solvent preventing the interaction between the radical and the reactive surface species inside the aggregates. Note that a small amount of reactive surface species is located on the outside of the aggregates, leading to slight decomposition of the biradicals, as indicated by a fairly short build-up time $\left(T_{\mathrm{B}, \mathrm{ON}}=6.1 \mathrm{~s}\right)$ but the latter is longer than in a bulk $16 \mathrm{mM}$ TEKPol solution $\left(T_{\mathrm{B}, \mathrm{ON}}=4 \mathrm{~s}\right)$. Hence, the destruction of the polarization agent is mainly avoided. The ${ }^{1} \mathrm{H}$ surface enhancement $\varepsilon_{\mathrm{C}}$, CP $\sim 30$ is lower than the bulk solvent enhancement which is a signature of polarization relay from outside the aggregates.

(IV) For $C_{\mathrm{BET}}>60$ and $c_{\mathrm{SOMF}}<0.075 \mathrm{mmol} \mathrm{g}^{-1}$ (3-low and 4low), a high solvent enhancement is detected $\left(\varepsilon_{\mathrm{H}}(o-\mathrm{DCB})=80\right)$, but the intensities of SOMF signals in ${ }^{13} \mathrm{C}$ CP MAS DNP SENS experiments remain weak (Fig. S5 and S6, ESI $\dagger$ ). The short build-up time $\left(T_{\mathrm{B}, \mathrm{ON}}=4.8 \mathrm{~s}\right)$, close to the value expected for bulk $16 \mathrm{mM}$ TEKPol, indicates that the polarizing agent does not interact with the reactive surface species. Indeed, the high $C_{\mathrm{BET}}$ leads to a good protection of the SOMF inside the aggregates,
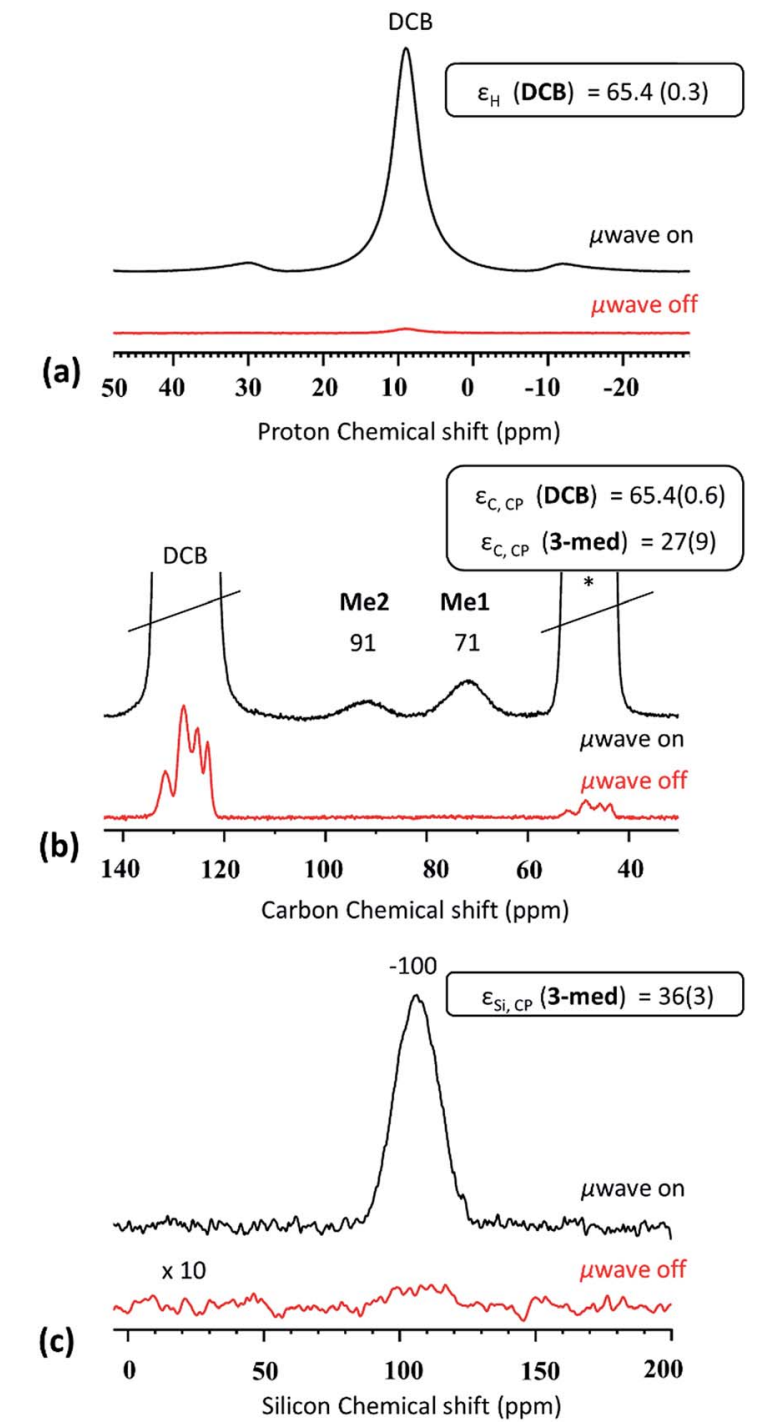

Fig. 3 (a) DNP SENS ${ }^{1} \mathrm{H}$ MAS, (b) ${ }^{13} \mathrm{C} \mathrm{CP} \mathrm{MAS} \mathrm{and} \mathrm{(c)}{ }^{29} \mathrm{Si} C P$ MAS $(100$ $\mathrm{K}, 400 \mathrm{MHz} / 263 \mathrm{GHz}$ gyrotron) of 3-med in $16 \mathrm{mM}$ TEKPol o-DCB solution obtained at $8 \mathrm{kHz}$ MAS. The red line represents the spectra without microwave irradiation ( $\mu$ wave off), and the black line represents experiments with microwave irradiation ( $\mu$ wave on). The stars indicate the spinning side band.

and the low SOMF concentration leads to a negligible quantity on the aggregate surface.

\section{Conclusions}

In conclusion, the propensity of silica NPs for aggregation can be controlled and yield high DNP SENS efficiency for reactive surface species. Differences in the DNP SENS results are attributed to the modification of the spatial properties of silica aggregates upon grafting of surface organometallic fragments. In the regime where hydrophilic nanoparticles form aggregates that allow the solvent (here $o$-DCB) to enter the interparticle space, but do not allow entry of the bulky TEKPol radicals (obtained when $C_{\mathrm{BET}}>60$ and the SOMF concentration is modest $\left.\left(\sim 0.13 \mathrm{mmol} \mathrm{g}_{\text {silica }^{-1}}\right)\right)$, enhancement factors of up to 30 are 
obtain for the reactive surface species. High SOMF concentrations $\left(c_{\mathrm{SOMF}}>0.2 \mathrm{mmol} \mathrm{g}_{\text {silica }}{ }^{-1}\right)$ lead to hydrophobic silica nanoparticles $\left(C_{\mathrm{BET}}<35\right)$ which are highly dispersed in the nonpolar solvent ( $o-\mathrm{DCB})$, and hence the SOMF is accessible for reaction with TEKPol, and DNP SENS cannot be applied. Similarly silica nanoparticles having a low SOMF concentration $\left(<0.10 \mathrm{mmol} \mathrm{g}_{\text {silica }}{ }^{-1}\right)$ remain hydrophilic $\left(C_{\mathrm{BET}}>60\right)$ and create aggregates where neither the TEKPol nor the solvent can enter the interparticle space, and DNP SENS is also inefficient. Contact of the solvent $o$-DCB with both SOMF and TEKPol is important to guarantee the transfer of polarization.

Finally, we note that the quality of the DNP SENS spectrum of SOMF 3 on silica nanoparticles (3-med) and encapsulated inside MCM41 (3-MCM41) ${ }^{27}$ is similar. However, the two approaches are complementary. The MCM41-based approach is tunable, but requires a specific synthetic approach, whereas the approach here can be applied to native systems if they fulfill the criteria for agglomeration, without inducing any change in catalytic activity.

\section{Conflicts of interest}

There are no conflicts to declare.

\section{Acknowledgements}

This work received support from the King Abdullah University of Science and Technology (KAUST) and the European Research Council (ERC Advanced Grant No. 320860). We thank Dr Olivier Ouari and Paul Tordo of the University of Aix-Marseille for providing the TEKPol radical.

\section{Notes and references}

1 J. D. A. Pelletier and J.-M. Basset, Acc. Chem. Res., 2016, 49, 664-677.

$2 \mathrm{C}$. Li and Y. Liu, Bridging Heterogeneous and Homogeneous Catalysis: Concepts, Strategies, and Applications, Wiley, 2014.

3 M. P. Conley, A. J. Rossini, A. Comas-Vives, M. Valla, G. Casano, O. Ouari, P. Tordo, A. Lesage, L. Emsley and C. Coperet, Phys. Chem. Chem. Phys., 2014, 16, 17822-17827.

4 B. Trewyn, Heterogeneous Catalysis for Today's Challenges: Synthesis, Characterization and Applications, Royal Society of Chemistry, 2015.

5 C. Coperet, M. Chabanas, R. P. Saint-Arroman and J. M. Basset, Angew. Chem., Int. Ed., 2003, 42, 156-181.

6 C. Copéret, D. P. Estes, K. Larmier and K. Searles, Chem. Rev., 2016, 116, 8463-8505.

7 A. Bendjeriou-Sedjerari, J. M. Azzi, E. Abou-Hamad, D. H. Anjum, F. A. Pasha, K. W. Huang, L. Emsley and J. M. Basset, J. Am. Chem. Soc., 2013, 135, 17943-17951.

8 A. Bendjeriou-Sedjerari, J. Sofack-Kreutzer, Y. Minenkov, E. Abou-Hamad, B. Hamzaoui, B. Werghi, D. H. Anjum, L. Cavallo, K.-W. Huang and J.-M. Basset, Angew. Chem., Int. Ed., 2016, 55, 11162-11166.

9 R. Anwander, Chem. Mater., 2001, 13, 4419-4438.
10 C. Copéret, A. Comas-Vives, M. P. Conley, D. P. Estes, A. Fedorov, V. Mougel, H. Nagae, F. Núñez-Zarur and P. A. Zhizhko, Chem. Rev., 2016, 116, 323-421.

11 L. T. Zhuravlev, Colloids Surf., A, 2000, 173, 1-38.

12 J.-M. Basset, E. Callens and N. Riache, in Handbook of Metathesis, Wiley-VCH Verlag GmbH \& Co. KGaA, 2015, pp. 33-70.

13 F. Blanc, C. Coperet, A. Lesage and L. Emsley, Chem. Soc. Rev., 2008, 37, 518-526.

14 A. Lesage, M. Lelli, D. Gajan, M. A. Caporini, V. Vitzthum, P. Miéville, J. Alauzun, A. Roussey, C. Thieuleux, A. Mehdi, G. Bodenhausen, C. Copéret and L. Emsley, J. Am. Chem. Soc., 2010, 132, 15459-15461.

15 M. Lelli, D. Gajan, A. Lesage, M. A. Caporini, V. Vitzthum, P. Mieville, F. Heroguel, F. Rascon, A. Roussey, C. Thieuleux, M. Boualleg, L. Veyre, G. Bodenhausen, C. Coperet and L. Emsley, J. Am. Chem. Soc., 2011, 133, 2104-2107.

16 A. J. Rossini, A. Zagdoun, M. Lelli, A. Lesage, C. Copéret and L. Emsley, Acc. Chem. Res., 2013, 46, 1942-1951.

17 M. P. Conley, R. M. Drost, M. Baffert, D. Gajan, C. Elsevier, W. T. Franks, H. Oschkinat, L. Veyre, A. Zagdoun, A. Rossini, M. Lelli, A. Lesage, G. Casano, O. Ouari, P. Tordo, L. Emsley, C. Copéret and C. Thieuleux, Chem.Eur. J., 2013, 19, 12234-12238.

18 W. R. Gruning, A. J. Rossini, A. Zagdoun, D. Gajan, A. Lesage, L. Emsley and C. Coperet, Phys. Chem. Chem. Phys., 2013, 15, 13270-13274.

19 O. Lafon, A. S. L. Thankamony, T. Kobayashi, D. Carnevale, V. Vitzthum, I. I. Slowing, K. Kandel, H. Vezin, J. P. Amoureux, G. Bodenhausen and M. Pruski, J. Phys. Chem. C, 2013, 117, 1375-1382.

20 M. P. Conley, C. Coperet and C. Thieuleux, ACS Catal., 2014, 4, 1458-1469.

21 N. Eedugurala, Z. Wang, U. Chaudhary, N. Nelson, K. Kandel, T. Kobayashi, I. I. Slowing, M. Pruski and A. D. Sadow, ACS Catal., 2015, 5, 7399-7414.

22 T. Gutmann, J. Liu, N. Rothermel, Y. Xu, E. Jaumann, M. Werner, H. Breitzke, S. T. Sigurdsson and G. Buntkowsky, Chem.-Eur. J., 2015, 21, 3798-3805.

23 I. Romanenko, D. Gajan, R. Sayah, D. Crozet, E. Jeanneau, C. Lucas, L. Leroux, L. Veyre, A. Lesage, L. Emsley, E. Lacote and C. Thieuleux, Angew. Chem., Int. Ed., 2015, 54, 12937-12941.

24 M. Werner, A. Heil, N. Rothermel, H. Breitzke, P. B. Groszewicz, A. S. Thankamony, T. Gutmann and G. Buntkowsky, Solid State Nucl. Magn. Reson., 2015, 72, 73-78.

25 B. Hamzaoui, A. Bendjeriou-Sedjerari, E. Pump, E. AbouHamad, R. Sougrat, A. Gurinov, K. W. Huang, D. Gajan, A. Lesage, L. Emsley and J. M. Basset, Chem. Sci., 2016, 7, 6099-6105.

26 T. C. Ong, W. C. Liao, V. Mougel, D. Gajan, A. Lesage, L. Emsley and C. Coperet, Angew. Chem., Int. Ed., 2016, 55, 4743-4747.

27 E. Pump, J. Viger-Gravel, E. Abou-Hamad, M. K. Samantaray, B. Hamzaoui, A. Gurinov, D. H. Anjum, D. Gajan, A. Lesage, 
A. Bendjeriou-Sedjerari, L. Emsley and J.-M. Basset, Chem. Sci., 2017, 8, 284-290.

28 W.-C. Liao, T.-C. Ong, D. Gajan, F. Bernada, C. Sauvee, M. Yulikov, M. Pucino, R. Schowner, M. Schwarzwalder, M. R. Buchmeiser, G. Jeschke, P. Tordo, O. Ouari, A. Lesage, L. Emsley and C. Coperet, Chem. Sci., 2017, 8, 416-422.

29 P. Berruyer, M. Lelli, M. P. Conley, D. L. Silverio, C. M. Widdifield, G. Siddiqi, D. Gajan, A. Lesage, C. Coperet and L. Emsley, J. Am. Chem. Soc., 2017, 139, 849-855.

30 K. P. de Jong, Synthesis of solid catalysts, John Wiley \& Sons, 2009.

31 G. J. Gerfen, L. R. Becerra, D. A. Hall, R. G. Griffin, R. J. Temkin and D. J. Singel, J. Chem. Phys., 1995, 102, 9494-9497.

32 K. W. Huang and R. M. Waymouth, J. Am. Chem. Soc., 2002, 124, 8200-8201.

33 T. Iwamoto, H. Masuda, S. Ishida, C. Kabuto and M. Kira, J. Am. Chem. Soc., 2003, 125, 9300-9301.

34 H. Takahashi, S. Hediger and G. De Paepe, Chem. Commun., 2013, 49, 9479-9481.

35 C. Fernández-de-Alba, H. Takahashi, A. Richard, Y. Chenavier, L. Dubois, V. Maurel, D. Lee, S. Hediger and G. De Paëpe, Chem.-Eur. J., 2015, 21, 4512-4517.

36 L. Piveteau, T. C. Ong, A. J. Rossini, L. Emsley, C. Coperet and M. V. Kovalenko, J. Am. Chem. Soc., 2015, 137, 1396413971.

37 K. G. Valentine, G. Mathies, S. Bédard, N. V. Nucci, I. Dodevski, M. A. Stetz, T. V. Can, R. G. Griffin and A. J. Wand, J. Am. Chem. Soc., 2014, 136, 2800-2807.

38 J. Viger-Gravel, P. Berruyer, D. Gajan, J.-M. Basset, A. Lesage, P. Tordo, O. Ouari and L. Emsley, Angew. Chem., Int. Ed., 2017, 56, 8726-8730.

39 W. R. Gunther, V. K. Michaelis, M. A. Caporini, R. G. Griffin and Y. Roman-Leshkov, J. Am. Chem. Soc., 2014, 136, 62196222.

40 F. A. Perras, L.-L. Wang, J. S. Manzano, U. Chaudhary, N. N. Opembe, D. D. Johnson, I. I. Slowing and M. Pruski, Curr. Opin. Colloid Interface Sci., 2018, 33, 9-18.

41 J. Beckmann, D. Dakternieks, A. Duthie, M. L. Larchin and E. R. T. Tiekink, Appl. Organomet. Chem., 2003, 17, $52-62$.

42 I. S. Chuang and G. E. Maciel, J. Phys. Chem. B, 1997, 101, 3052-3064.

43 L. Bergstrom, Adv. Colloid Interface Sci., 1997, 70, 125-169.

44 B. Vincent, Z. Király, S. Emmett and A. Beaver, Colloids Surf., 1990, 49, 121-132.

45 D. H. Lee, J. Jeong, S. W. Han and D. P. Kang, J. Mater. Chem. A, 2014, 2, 17165-17173.

46 S. D. Bhagat, Y.-H. Kim, K.-H. Suh, Y.-S. Ahn, J.-G. Yeo and J.-H. Han, Microporous Mesoporous Mater., 2008, 112, 504509.

47 N. Rakhshan and M. Pakizeh, Korean J. Chem. Eng., 2015, 32, 2524-2533.

48 R. P. Bagwe, L. R. Hilliard and W. Tan, Langmuir, 2006, 22, 4357-4362.
49 A. J. Worthen, V. Tran, K. A. Cornell, T. M. Truskett and K. P. Johnston, Soft Matter, 2016, 12, 2025-2039.

50 A. Zagdoun, A. J. Rossini, M. P. Conley, W. R. Gruning, M. Schwarzwalder, M. Lelli, W. T. Franks, H. Oschkinat, C. Coperet, L. Emsley and A. Lesage, Angew. Chem., Int. Ed., 2013, 52, 1222-1225.

51 L. Jelinek and E. S. Kovats, Langmuir, 1994, 10, 4225-4231.

52 D. Brunel, A. Cauvel, F. Di Renzo, F. Fajula, B. Fubini,

B. Onida and E. Garrone, New J. Chem., 2000, 24, 807-813.

53 J. A. Osaheni and S. T. Buddle, US Pat., 6193412 B1, 2001.

54 M. K. Samantaray, E. Callens, E. Abou-Hamad, A. J. Rossini,

C. M. Widdifield, R. Dey, L. Emsley and J. M. Basset, J. Am. Chem. Soc., 2014, 136, 1054-1061.

55 E. Le Roux, M. Taoufik, M. Chabanas, D. Alcor, A. Baudouin, C. Coperet, J. Thivolle-Cazat, J. M. Basset, A. Lesage, S. Hediger and L. Emsley, Organometallics, 2005, 24, 42744279.

56 M. Adachi, C. Nédez, X. X. Wang, F. Bayard, V. Dufaud, F. Lefebvre and J.-M. Basset, J. Mol. Catal. A: Chem., 2003, 204, 443-455.

57 F. Bini, C. Rosier, R. P. Saint-Arroman, E. Neumann, C. Dablemont, A. de Mallmann, F. Lefebvre, G. P. Niccolai, J. M. Basset, M. Crocker and J. K. Buijink, Organometallics, 2006, 25, 3743-3760.

58 K. C. Szeto, A. Gallo, S. Hernández-Morejudo, U. Olsbye, A. De Mallmann, F. Lefebvre, R. M. Gauvin, L. Delevoye, S. L. Scott and M. Taoufik, J. Phys. Chem. C, 2015, 119, 26611-26619.

59 A. Hamieh, R. Dey, M. K. Samantaray, S. Abdel-Azeim, E. Abou-Hamad, Y. Chen, J. D. A. Pelletier, L. Cavallo and J.-M. Basset, Organometallics, 2016, 35, 2524-2531.

60 J. J. Yuan, S. X. Zhou, G. X. Gu and L. M. Wu, J. Mater. Sci., 2005, 40, 3927-3932.

61 Z. Cao, Y. Peng, S. Li, L. Liu and T. Yan, J. Phys. Chem. C, 2009, 113, 3096-3104.

62 N. Choudhury and B. M. Pettitt, J. Am. Chem. Soc., 2005, 127, 3556-3567.

63 R. Zangi, M. Hagen and B. J. Berne, J. Am. Chem. Soc., 2007, 129, 4678-4686.

64 A. Zagdoun, A. J. Rossini, D. Gajan, A. Bourdolle, O. Ouari, M. Rosay, W. E. Maas, P. Tordo, M. Lelli, L. Emsley, A. Lesage and C. Coperet, Chem. Commun., 2012, 48, 654656.

65 J. R. Yarava, S. R. Chaudhari, A. J. Rossini, A. Lesage and L. Emsley, J. Magn. Reson., 2017, 277, 149-153.

66 A. C. Pinon, J. Schlagnitweit, P. Berruyer, A. J. Rossini, M. Lelli, E. Socie, M. X. Tang, T. Pham, A. Lesage, S. Schantz and L. Emsley, J. Phys. Chem. C, 2017, 121, 15993-16005.

67 D. L. Silverio, H. A. van Kalkeren, T.-C. Ong, M. Baudin, M. Yulikov, L. Veyre, P. Berruyer, S. Chaudhari, D. Gajan, D. Baudouin, M. Cavaillés, B. Vuichoud, A. Bornet, G. Jeschke, G. Bodenhausen, A. Lesage, L. Emsley, S. Jannin, C. Thieuleux and C. Copéret, Helv. Chim. Acta, 2017, 100, e1700101. 